$$
\text { ECOTOX - Brazil }
$$

\title{
Análise Ecotoxicológica em Viveiro de Produção de Tilápia (Oreochromis niloticus), Utilizando o Cladócero Ceriodaphnia dubia como Organismo-Teste
}

\author{
R. Bazante-Yamaguishi ${ }^{*}$, J. V. Lombardi ${ }^{2}$, C. T. J. Mercante ${ }^{2}$, \\ N. P. P. Caruso ${ }^{1}$, L. E. B. Moreira ${ }^{1} \&$ J. S. Pereira ${ }^{1}$ \\ ${ }^{1}$ Programa de Pós-graduação em Aqüicultura e Pesca - Instituto de Pesca - \\ APTA - SAA- SP Av. Francisco Matarazzo, 455 - CEP 05001-900, São Paulo, SP - Brasil \\ ${ }^{2}$ Centro de Pesquisa e Desenvolvimento em Recursos Hídricos \\ (Laboratório de Ecotoxicologia Aquática) - Instituto de Pesca, São Paulo, SP - Brasil
}

(Received April 24, 2008; Accepted December 19, 2008)

\begin{abstract}
RESUMO
Durante os meses de novembro de 2006 a março de 2007 um viveiro povoado com tilápias do Nilo (Oreochromis niloticus), do

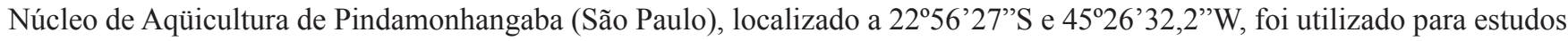
ecotoxicológicos (testes agudo e crônico) com Ceriodaphnia dubia para avaliar a qualidade da água à montante do viveiro $(\mathrm{P} 1)$, dentro do viveiro $(\mathrm{P} 2)$, no efluente $(\mathrm{P} 3)$, na sua mistura com o corpo hídrico receptor $(\mathrm{P} 4)$, em sua montante $(\mathrm{P} 5)$ e à sua jusante (P6). Somente o efluente (P3) foi analisado em cinco concentrações. Os métodos estatísticos utilizados foram a prova exata de Fisher, ANOVA (método Dunnett) e ICp. A média da sobrevivência dos organismos-teste para o grupo controle foi de $89,80 \%$, com número médio de 20 neonatos/fêmea e coeficiente de variação de $28,1 \%$. Os valores médios de CENO e CEO $(\mathrm{p}<0,05)$ e de $\mathrm{CI}_{50}$ para o efluente (P3) testado foram de 50,0\%, 100,0\% e 50,13\%, respectivamente. Os resultados obtidos demonstraram que houve toxicidade em todos os pontos, indicando a necessidade de tratamentos para o afluente e efluente.

Palavras-chave: Ceriodaphnia dubia, ecotoxicologia, efluente, Oreochromis niloticus, piscicultura, tilápia do Nilo.
\end{abstract}

\section{ABSTRACT \\ Ecotoxicologycal Assessment of a Fish Farming Pond of Tilapia (Oreochromis niloticus), Using the Cladocera Ceriodaphnia dubia as Test-Organism}

From November 2006 to March 2007, a pond used for rearing Nile tilapia (Oreochromis niloticus), located at the Experimental

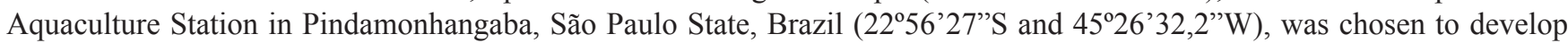
studies focused on ecotoxicology (acute and chronic tests) with Ceriodaphnia dubia in order to evaluate the water quality from six different sites of sampling: the fish farming upstream, inside fish pond, its effluent, the mixing zone (site related to the mixture of the effluent with the receiving water), and upstream and downstream of the receiving water. Only the effluent was analyzed in five concentrations. Statistical methods employed were Fisher's exact test, ANOVA (Dunnett's method) and ICp. Survival average of test-organisms from the control group was $89.80 \%$ with an average of 20 neonates/female, and coefficient of variation $28.05 \%$. Average values for NOEC and LOEC ( $p<0.05$ ), and $\mathrm{IC}_{50}$ for the effluent tested were $50.0 \%, 100.0 \%$ and $50.13 \%$, respectively. Results have demonstrated toxic effect in all sites of sampling, and it indicates that treatments of inflow water and effluent are necessary.

Keywords: Ceriodaphnia dubia, ecotoxicology, effluent, fish farming, Nile tilapia, Oreochromis niloticus. 


\section{INTRODUÇÃO}

O crescimento demográfico implica na exploração e na utilização da água, resultando no aumento de todo tipo de águas residuárias. Um dos fatores envolvidos na deterioração dos recursos hídricos é a falta de tratamento dos efluentes lançados em seu percurso (Braga et al., 2004).

Embora o Brasil possua cerca de $12 \%$ do total de água doce do planeta (Valenti, 2007), atualmente, podemos notar diminuição da disponibilidade e qualidade das águas, com o aumento das atividades, vistas como impactantes, que muitas vezes são evidentes e/ou agravadas por: (a) atividades realizadas em locais indevidos ou que não oferecem condições propícias ao seu desenvolvimento; (b) quando seus recursos naturais estão limitados; ou (c) quando o seu manejo está mal gerenciado.

Em relação à prática de aqüicultura continental, que utiliza a água como importante recurso para a produção de alimentos, dados do Instituto Brasileiro do Meio Ambiente e dos Recursos Naturais Renováveis - IBAMA (2005) mostram que a produção brasileira em todos os estados é de, aproximadamente, $180 \mathrm{mil}$ ton/ano e é composta, principalmente, pela piscicultura. Desse montante, 38\% (68 mil ton/ano) referem-se à criação de tilápia.

Estudos sobre abordagens concernentes aos parâmetros de qualidade da água na aqüicultura encontram-se contemplados em diversas produções bibliográficas, dentre as quais se destacam: Boyd (1990), Boyd \& Tucker (1998), Kubitza (1999), Sipaúba-Tavares \& Rocha (2003), Queiroz \& Silveira (2006) e Valenti (2007), que além dos cuidados com a seleção de água para abastecimento de viveiros, passaram a incluir a preocupação com a carga de poluentes dos efluentes gerados nesta atividade, lançados nos corpos d'água sem prévio tratamento, poluindo-os e prejudicando a vida aquática.

Em paises desenvolvidos, tratamentos de efluentes gerados pela piscicultura como o sistema "wetland", que têm a função de biofiltro, já estão sendo realizados, resultando numa redução significativa de macronutrientes, como o nitrogênio e fósforo, principais causadores de eutrofização de ambientes aquáticos (Porrello et al., 2003).

Durante o processo de produção, é inevitável o acúmulo de resíduos orgânicos e metabólicos nos tanques e viveiros de piscicultura, onde o sistema de renovação de água é intermitente (UNEP-IETC, 2001). Além disso, a falta de conhecimento sobre manejo sanitário adequado, uso de drogas, vacinas e outras profilaxias para o tratamento e/ou prevenção de doenças nos viveiros, podem acarretar a propagação de microrganismos patógenos aquáticos e o aumento de substâncias químicas e suas misturas, como fonte de contaminação hídrica, colocando em risco as comunidades aquáticas naturais.

Por meio da análise ecotoxicológica é possível avaliar os riscos decorrentes de amostras ambientais contaminadas e alertar para o potencial de efeitos deletérios ao meio ambiente.. Este tipo de análise vem servindo como importante ferramenta para preservação e recuperação de ecossistemas aquáticos naturais (Oliveira-Neto, et al., 2000). Embora a avaliação de toxicidade de misturas ainda precise ser melhor explorada pela ecotoxicologia (Tomita et al., 2004), as substâncias produzidas em viveiros de aqüicultura merecem receber atenção em estudos desta natureza.

A piscicultura, de acordo com Pillay (1992), não pode ser caracterizada como atividade de grande potencial para gerar impacto ambiental, pois os seus efluentes, quando comparados aos efluentes de origem doméstica, em várias análises físicas e químicas, têm revelado menores teores de nutrientes.Além disso, a piscicultura é uma prática que, de certa forma, evita a captura de peixes em ambientes naturais, reduz a probabilidade de extinção de algumas espécies e aumenta a produção local, possibilitando uma fonte de renda para muitas pessoas. Porém, seu manejo deve seguir técnicas e controles adequados para evitar o aumento de resíduos, assim como a introdução de microrganismos patógenos e de produtos químicos relacionados, garantindo, assim, a sua sustentabilidade e o atendimento da demanda do mercado consumidor de pescados.

Desde o início do século passado, a legislação e políticas no Brasil buscam consolidar estratégias para valorização de seus recursos hídricos (CETESB, 2007). Há algumas décadas, o controle da poluição em corpos hídricos vinha sendo exercido, com base somente nos parâmetros estipulados pela resolução no 20 de 1986 do Conselho Nacional do Meio Ambiente (CONAMA), para as variáveis físicas e químicas. A nova resolução de número 357, de 17 de Março de 2005 do CONAMA, recomenda que as águas da União (doces, salobras e salinas) devem atender exigências de níveis de qualidade e padrões específicos para garantir seus usos preponderantes em cada classe e estabelece, além dos parâmetros físicos e químicos, a necessidade da realização de testes ecotoxicológicos em efluentes líquidos para a verificação dos possíveis efeitos tóxicos (agudo ou crônico) a organismos aquáticos.

Tendo em vista a pequena quantidade de informações disponíveis sobre este contexto, o presente estudo visou analisar a qualidade da água, ao longo de um ciclo de cultivo de tilápia, da espécie Oreochromis niloticus, através de ensaios ecotoxicológicos com Ceriodaphnia dubia, investigando os possíveis impactos oriundos desta atividade.

\section{MATERIAL E MÉTODOS}

\section{Caracterização da área de estudo}

O local selecionado para a avaliação foi um empreendimento de pesquisa científica da área de Aqüicultura, pertencente ao Pólo Regional de Desenvolvimento Tecnológico dos Agronegócios do Vale do Paraíba da Agência Paulista de Tecnologia dos Agronegócios, órgão vinculado à Secretaria de Agricultura e Abastecimento do Estado de São Paulo, no município de Pindamonhangaba $\left(22^{\circ} 56^{\prime} 27^{\prime \prime} \mathrm{S}\right.$ e $45^{\circ} 26^{\prime} 32,2^{\prime \prime} \mathrm{W}$ e altitude de $575 \mathrm{~m}$ ). O viveiro possuía área de $1.500 \mathrm{~m}^{2}$, profundidade média de $1,57 \mathrm{~m}$ e volume de $2.352 \mathrm{~m}^{3}$, com vazão aproximada de $2,7 \mathrm{~L} \mathrm{~s}^{-1}$, manejado em sistema semi-intensivo de criação de tilápias do Nilo (Oreochromis niloticus). A fonte de abastecimento do sistema era a Represa do Borba, classificada como águas de Classe 2, conforme CONAMA (2005). Esta mesma fonte também distribuía água para outros viveiros existentes no local, incluindo tanques de alevinagem, pré-engorda, engorda e reprodução. O sistema de renovação de água do viveiro 
era constante e sem aeração mecânica. $\mathrm{O}$ efluente gerado era descartado no corpo receptor do Ribeirão do Borba, águas de Classe 2 (CONAMA, 2005), sendo afluente do Ribeirão do Curtume, que por sua vez, forma uma das sub-bacias do Rio Paraíba do Sul, que de acordo com CETESB (2007), é o principal rio pertencente à Unidade de Gerenciamento de Recursos Hídricos 2, da região sudeste do Brasil.

Informações colhidas no local permitiram o registro dos seguintes procedimentos de preparo do viveiro: (a) calagem como medida profilática e (b) fertilização química com superfosfato simples e sulfato de amônia, respectivamente, nas quantidades de $6 \mathrm{~g} \mathrm{~m}^{-2}$ e $4 \mathrm{~g} \mathrm{~m}^{-2}$.

O povoamento do viveiro foi realizado com 3.750 juvenis machos de tilápia do Nilo, com peso médio aproximado de $30 \mathrm{~g}$. Os peixes receberam como alimento ração extrusada da marca $\mathrm{ADIMAX}^{\circledR}$, com proteína bruta igual a $28 \%$ (informação de rótulo), oferecida duas vezes ao dia, na proporção de $3 \%$ do peso vivo/dia. Os resultados observados em termos de produção, ao final do cultivo, revelaram valores com peso médio individual aproximado de $670 \mathrm{~g}$ e conversão alimentar aparente de 1,72:1, consumindo-se $3.650 \mathrm{~kg}$ de ração para uma produção de $2.120 \mathrm{~kg}$ de peixe, correspondendo a uma produtividade de $14.133 \mathrm{~kg}$ de peixe/ha/ciclo, com rendimento de $84,38 \%$.
As coletas de água foram realizadas, mensalmente, no período de novembro de 2006 a março de 2007, em seis pontos amostrais (Figura 1): ponto $\mathrm{P} 1$ à montante do viveiro (fonte de abastecimento); ponto $\mathrm{P} 2$ região limnética do viveiro (corpo central); ponto P3 efluente do viveiro (no sistema de drenagem); ponto P4 a mistura (no local de lançamento do efluente no corpo receptor); ponto P5 à montante do ponto de mistura (acesso a 11 metros de distância) e ponto P6 à jusante do ponto de mistura (acesso a 13 metros de distância). Todas as amostras da subsuperfície da coluna d'água foram coletadas durante o período matutino e transportadas em vasilhames de polietileno de 2 litros, previamente descontaminados. Durante o transporte, as amostras foram acondicionadas, em caixas isotérmicas refrigeradas, sob temperatura próxima de $4{ }^{\circ} \mathrm{C}$. A frequiência amostral incluiu uma coleta ao mês (C1 a C6), com exceção do mês de março, onde foram efetuadas duas coletas (dias 07 e 12), devido à antecipação do encerramento do cultivo. Os resultados de março foram apresentados utilizando índices numéricos (1) e (2) para distinguir essas coletas. O local de processamento das análises limnológicas foi o Laboratório de Análises Físicas e Químicas da Água, da Unidade Laboratorial de Referência em Limnologia - Centro de Pesquisa e Desenvolvimento em Recursos Hídricos do Instituto de Pesca de São Paulo.

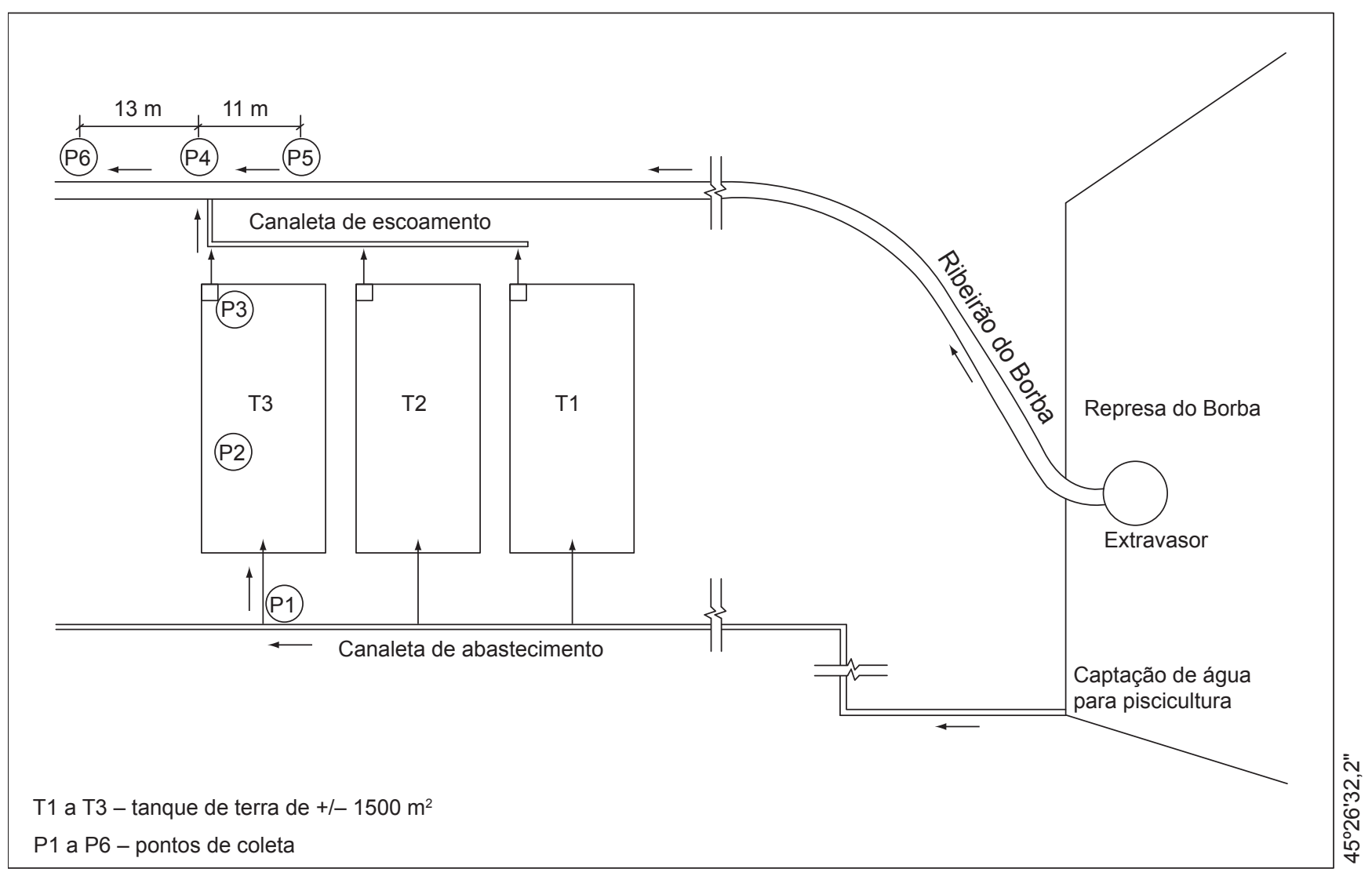


No laboratório, as amostras foram filtradas com rede de zooplâncton $(60 \mu \mathrm{m})$, para a remoção de possíveis organismos predadores, que porventura pudessem interferir negativamente nos ensaios e, com a impossibilidade de realização imediata dos testes, essas amostras eram acondicionadas em "freezer", sob temperatura próxima de $-18{ }^{\circ} \mathrm{C}$, por um período não superior a 60 dias, conforme recomendado pela ABNT (2005).

Os ensaios físicos e químicos foram realizados de acordo com as recomendações de padronizações nacionais e internacionais descritos em American Public Health Association (APHA et al., 2005) para as seguintes variáveis limnológicas: fósforo total $\left(\mathrm{mg} \mathrm{L}^{-1}\right)$, nitrogênio total $\left(\mathrm{mg} \mathrm{L}^{-1}\right)$, nitrogênio amoniacal total $\left(\mathrm{mg} \mathrm{L}^{-1}\right)$, nitrito e nitrato $\left(\mu \mathrm{g} \mathrm{L}^{-1}\right)$, dureza total e alcalinidade total $\left(\mathrm{mg} \mathrm{L}^{-1} \mathrm{de} \mathrm{CaCO}_{3}\right)$. Outras análises, realizadas diretamente no campo, incluíram os seguintes registros: transparência $(\mathrm{m})$, medida somente no ponto $\mathrm{P}$ 2, através do Disco de Secchi; vazão $\left(\mathrm{L} \mathrm{s}^{-1}\right)$ para os pontos $\mathrm{P} 1$, P3 e P5; além das temperaturas da água e do $\operatorname{ar}\left({ }^{\circ} \mathrm{C}\right)$, potencial hidrogeniônico $-\mathrm{pH}$, oxigênio dissolvido $\left(\mathrm{mg} \mathrm{L}^{-1}\right)$ e turbidez (UNT), medidos por meio de sonda de multiparâmetros Horiba U-22, em todos os pontos amostrais. De acordo com Bower \& Bidwell (1978) foi realizado o cálculo da amônia na sua forma não ionizada $\left(\mathrm{NH}_{3}-\mathrm{N}\right)$ para amostras com $\mathrm{pH}$ abaixo de 7,0 e temperatura da água variando entre 20 a $31^{\circ} \mathrm{C}$. Para a clorofila $a\left(\mu \mathrm{g} \mathrm{L}^{-1}\right)$ foi utilizada a técnica de extração dos pigmentos, através do solvente orgânico etanol ( $90 \%)$, conforme o método de Sartory \& Grobbelaar (1984). As recomendações apresentadas por Mercante \& Tucci-Moura (1999) serviram para calcular o índice de estado trófico de Carlson (1977), alterado por Kratzer \& Brezonik (1981), o qual foi ajustado para ambientes tropicais (Tabela 1).

Dados meteorológicos regionais foram obtidos junto à Plataforma de Coletas de Dados (PCD) do Instituto Agronômico de Pindamonhangaba (APTA, 2007), incluindo registros de precipitação pluviométrica (somente dos dias de coleta e dos 11 dias que antecederam a mesma, totalizando 12 dias, que é valor do tempo estimado de residência da água no viveiro em estudo). Dessa maneira, foi avaliada com maior precisão a influência da água "adicional", provinda das chuvas às amostras dos ensaios ecotoxicológicos. Além disso, ao entorno do empreendimento foram identificadas algumas fontes pontuais e não pontuais de aporte de poluentes, para corroborar os resultados desse estudo.

\section{Ensaios ecotoxicológicos}

Os ensaios ecotoxicológicos foram realizados no Laboratório de Ecotoxicologia Aquática do Instituto de Pesca (SP). O

Tabela 1 - Classificação do Índice de Estado Trófico (IET), segundo CARLSON (1977), KRATZER e BREZONIK (1981).

\begin{tabular}{lc}
\hline Estado trófico & IET \\
\hline Ultra-oligotrófico & $<20$ \\
Oligotrófico & $21-40$ \\
Mesotrófico & $41-50$ \\
Eutrófico & $51-60$ \\
Hipereutrófico & $>60$ \\
\hline
\end{tabular}

organismo-teste utilizado foi a Ceriodaphnia dubia (Crustacea: Cladocera), cuja espécie é comumente recomendada para ensaios desta natureza Lombardi (2004). A água utilizada para o cultivo dos organismos, bem como para a diluição de amostras, foi de fonte natural, coletada no Ribeirão do Piraí, no município de Salto de Itu (SP), e filtrada em duas etapas: a primeira em rede de zooplâncton $(60 \mu \mathrm{m})$ e a segunda em papel filtro qualitativo. Seus aspectos de qualidade e indicação para o uso foram previamente atestados antes e durante os ensaios, conforme ABNT (2005), pelo Laboratório de Ecotoxicologia do Instituto de Pesca (SP) e também por outros laboratórios como o da Companhia de Tecnologia de Saneamento Ambiental-CETESB e o Laboratório de Ecologia e Ecotoxicologia Aquática do Instituto de Pesquisas Energéticas e Nucleares do Brasil - IPEN. As condições dos ensaios de toxicidade aguda e crônica seguiram um sistema semi-estático de 7 dias, conforme protocolo da NBR-13373 (ABNT, 2005). Assim, a troca total da amostra e recipiente ocorria, diariamente, a partir de 48 horas decorridas de seu início. Dez réplicas foram conduzidas, simultaneamente, para cada ponto coletado (P1 a P6) e apenas um organismo com idade inicial de 6 a 24 horas (neonato) foi adicionado para cada réplica, incluindo o grupo controle. Como alimento utilizou-se $0,02 \mathrm{~mL} /$ organismo de ração fermentada com teor de $2,50 \mathrm{~g} \mathrm{~L}^{-1}$ de sólidos-totais e $0,04 \mathrm{~mL} /$ organismo de suspensão de microalgas da espécie Pseudokirchneriella subcaptata (clorofícea), na proporção de $2,0 \times 10^{5}$ células $\mathrm{mL}^{-1}$, de acordo com a ABNT (2005).

Os recipientes-testes foram acondicionados em incubadora com temperatura média de $25,0 \pm 0,7^{\circ} \mathrm{C}$, fotoperíodo de 16 horas claro: 8 horas escuro e luminosidade de 1.000 lux. Todos os pontos foram testados em sua amostra bruta, ou seja, em sua maior concentração (100\%), exceto o ponto P3, que além da sua amostra bruta, foi analisado em outras quatro concentrações: $6,2 \%, 12,5 \%, 25,0 \%$ e $50,0 \%$. Todas essas concentrações foram preparadas em balões volumétricos e diluídas com a água de cultivo.

A validação dos ensaios foi realizada pela constatação, no grupo controle, de taxa de sobrevivência igual ou superior a $80 \%$, além da observação da média mínima reprodutiva de 12 neonatos por organismo genitor (ABNT, 2005).

\section{Análise estatística}

De acordo com a USEPA (2002), aplicou-se a prova exata de Fisher para as constatações de efeito tóxico agudo, nas comparações feitas entre os registros de mortalidade obtidos nos pontos amostrais, em relação ao grupo controle. Em seguida, a análise de variância (ANOVA) empregando o método Dunnett para as constatações de efeito tóxico crônico, nas comparações feitas entre os registros de quantificação reprodutiva (número de neonatos) obtidos nos pontos amostrais, contra aqueles observados no grupo controle. Todas estas análises foram realizadas, através do programa estatístico TOXTAT 3.3 (Gulley et al., 1991). As diferenças estatísticas foram consideradas significativas sempre que $\mathrm{p}<0,05$.

Os valores da Concentração de Efeito não Observado (CENO) e da Concentração de Efeito Observado (CEO) foram 
estimados, a partir da constatação da existência de diferença estatística significativa entre uma determinada concentração do efluente e o grupo controle. Além disso, a concentração mediana de inibição da reprodução $\left(\mathrm{CI}_{50 ; 168 \mathrm{~h}}\right)$ foi calculada, através do método de Interpolação Linear, disponível no programa $\mathrm{IC}_{\mathrm{P}}$ (Norberg-King, 1993).

\section{RESULTADO E DISCUSSÃO}

\section{Avaliação da Toxicidade}

Os resultados das análises ecotoxicológicas de todas as coletas demonstraram, de forma geral, toxicidades agudas e crônicas para todos os pontos, com exceção do ponto P1, da $6^{\text {a }}$ coleta (C6) que apresentou resultado de ausência de toxicidade, conforme Figura 2. O efluente (P3) apresentou a maior incidência de toxicidade aguda para Ceriodaphnia dubia, $83,3 \%$; seguido dos pontos P1, P4 e P5 com incidência igual a $66,7 \%$; o ponto $\mathrm{P} 2$, com valor de $50 \%$ das coletas e o ponto P6, a menor incidência com 33,3\%.

Avaliando somente o ponto $\mathrm{P} 3$ e suas respectivas concentrações 6,2\%, 12,5\%, 25,0\%, 50,0\% e 100,0\% (Figura 3), verificou-se que a incidência encontrada para resposta de sobrevivência dos organismos-teste foi de $16,7 \%$ para concentração de $100,0 \%$. Em seguida, estão as demais concentrações que obtiveram valores entre $66,7 \%$ e $83,3 \%$. Em relação à toxicidade crônica, o valor de CENO, para a média geral, foi observado na concentração de $50 \%$ e o valor de CEO foi à concentração de $100 \%$.

A Concentração de Inibição da reprodução de $50 \%$ dos organismos-teste $\left(\mathrm{CI}_{50 ; 168 \mathrm{~h}}\right)$ e o limite de confiança para cada amostra, estão representados na Figura 4, observando que a

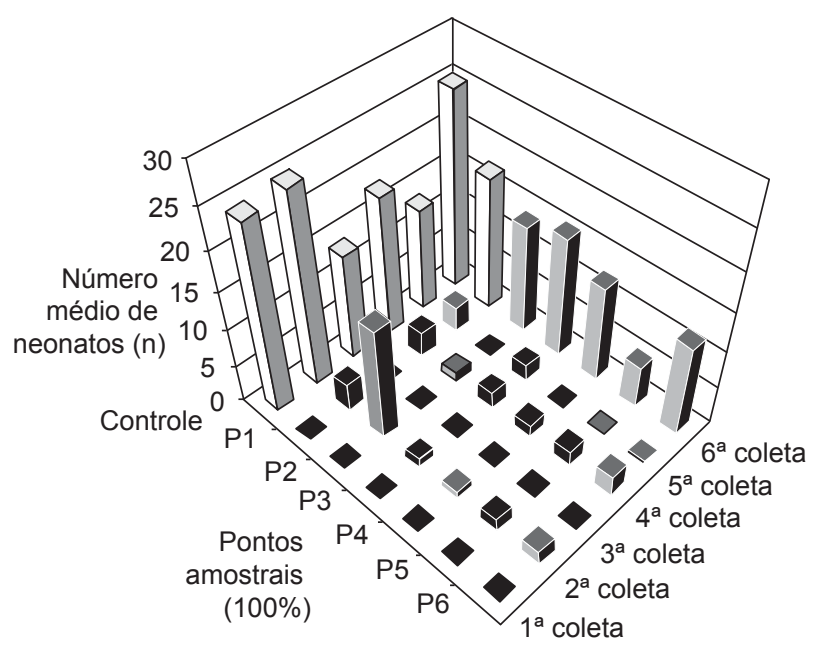

$$
\begin{aligned}
& \square \text { Ausência de toxicidade } \\
& \square \text { Toxicidade crônica } \\
& \square \text { Toxicidade aguda }
\end{aligned}
$$

Figura 2 - Representação gráfica da média de toxicidade nos pontos de amostragem e ao longo do período de cultivo de tilápias do Nilo (O. niloticus). amostra do mês de março (2) não possui valor para $\mathrm{CI}_{50}$, porque as diluições testadas naquela coleta não resultaram em inibições acima de 50\%. A média geral entre esses valores foi calculada, resultando num valor igual a $\mathrm{CI}_{50 ; 168 \mathrm{~h}}$ de $50,13 \%$ (como indica a seta na Figura 3).

\section{Análises físicas e químicas}

A temperatura do ar, nas datas das coletas, oscilou entre 21,0 e $31,7^{\circ} \mathrm{C}$ e a da água situou-se entre 20,7 e $31,3^{\circ} \mathrm{C}$. A média obtida da transparência $(\mathrm{m})$ para o ponto $\mathrm{P} 2$ foi de $0,32 \pm 0,06$. Os resultados médios da vazão $\left(\mathrm{L} \mathrm{s}^{-1}\right)$ para os pontos $\mathrm{P} 1$ e P3 foram de 2,76 $\pm 0,85$ e 2,25 $\pm 0,90$, respectivamente. À montante do ponto de mistura (P5) obtiveram-se valores de vazão variando de 36 a $2040 \mathrm{~L} \mathrm{~s}^{-1}$. Os resultados das demais variáveis físicas e químicas obtidas encontram-se registrados na Tabela 2, assim como as recomendações da Resolução do CONAMA (2005), especificamente para águas de classe 2.

\section{Determinantes da toxicidade}

Durante os ensaios, os valores de $\mathrm{pH}$ das amostras (Tabela 2) resultaram muito abaixo da média do grupo controle, que sofreu ajustes nas variáveis físicas e químicas (Tabela 3) para atender as especificações do teste com o cladócero, conforme ABNT (2005). No limite estabelecido de $\mathrm{pH}$, CONAMA (2005), as amostras atenderam às especificações. Porém, de acordo com a ABNT (2005), o pH estava abaixo do valor recomendado (de 7,0 a 7,6), para a manutenção dos

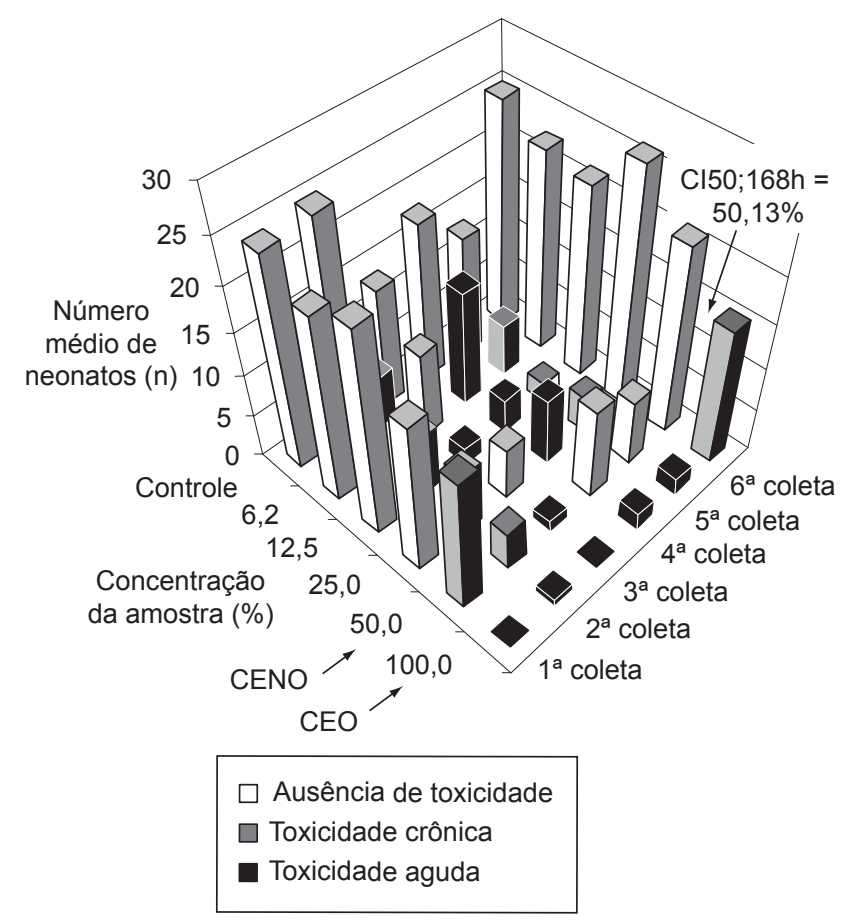

Figura 3 - Representação gráfica da toxicidade das diferentes diluições do efluente (P3) ao longo do período de cultivo de tilápias do Nilo (O. niloticus). CENO: concentração de efeito não observado; CEO: concentração de efeito observado. $\mathrm{CI}_{50}$ : concentração de inibição mediana. 
ensaios com C. dubia, o que pode ser um fator abiótico de interferência nos resultados.

Em todas as coletas, os níveis de dureza foram bastante baixos (Tabela 2), enquadrando-se nas classificações feitas por

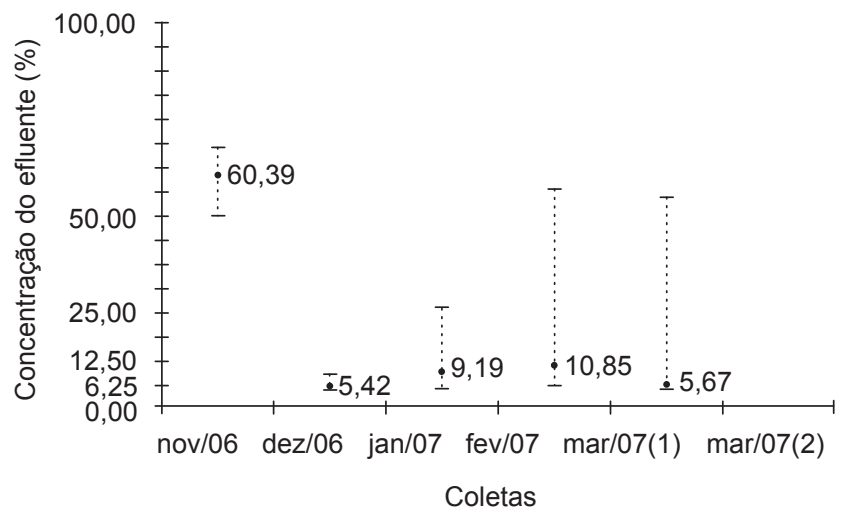

Figura 4 - Interpolação linear para a concentração de inibição mediana $\left(\mathrm{CI}_{50: 168 \mathrm{~h}}\right)$ das diluições do ponto $\mathrm{P} 3$ durante as coletas. (1): $1^{\mathrm{a}}$ coleta do mês; (2): $2^{\mathrm{a}}$ coleta do mês.
Lewis et al. (1994) apud Domingues \& Bertoletti (2006) como água "muito mole" ou apenas "mole". Como a água apresentava concentração de sais minerais abaixo do recomendado ao teste com Ceriodaphnia dubia, a falta de algum composto iônico nas amostras poderia também ter interferido nos resultados de toxicidade. Cowgill \& Milazzo (1991) realizaram uma série de ensaios visando à determinação da toxicidade, em soluções-teste com diferentes salinidades, durezas e alcalinidades, verificando a taxa de reprodução para esta espécie. Os autores concluíram que esse cladócero é mais sensível à variação da dureza do que da alcalinidade e menos sensível à variação de salinidade, notando também que a espécie supracitada é mais sensível que Daphnia magna às variações desses três parâmetros químicos.

A condutividade corrobora a constatação dos baixos valores de dureza, servindo também como um indicativo do nível de sais minerais na água. Portanto, uma vez constatada a deficiência destes nutrientes essenciais ao organismo-teste em questão, podemos considerar que esta variável indicaria uma forma de manifestação de toxicidade (aguda ou crônica) com a probabilidade da existência de efeitos potencializadores sob o metabolismo dos organismos (sinergismo) ou um efeito contrário

Tabela 2 - Resultados das análises físicas e químicas nos pontos de amostragem (média \pm desvio-padrão) e valores recomendados pelo CONAMA (2005) para as águas doces de Classe 2 e os valores recomendados para o lançamento de efluentes em geral nessa mesma Classe.

\begin{tabular}{|c|c|c|c|c|c|c|c|c|}
\hline \multirow[t]{2}{*}{ Variáveis } & \multirow[t]{2}{*}{ P1 } & \multirow[t]{2}{*}{$\mathbf{P 2}$} & \multirow[t]{2}{*}{$\mathbf{P 3}$} & \multirow[t]{2}{*}{$\mathbf{P 4}$} & \multirow[t]{2}{*}{ P5 } & \multirow[t]{2}{*}{ P6 } & \multicolumn{2}{|c|}{ CONAMA 357/05 } \\
\hline & & & & & & & Classe 2 & Efluente (P3) \\
\hline Temperatura da água $\left({ }^{\circ} \mathrm{C}\right)$ & $\begin{array}{c}26,93 \pm \\
3,05\end{array}$ & $\begin{array}{c}28,26 \pm \\
2,80\end{array}$ & $\begin{array}{c}27,66 \pm \\
2,58\end{array}$ & $\begin{array}{c}25,26 \pm \\
2,39\end{array}$ & $\begin{array}{c}24,62 \pm \\
2,10\end{array}$ & $\begin{array}{c}25,20 \pm \\
2,27\end{array}$ & $* *$ & 40 \\
\hline $\mathrm{pH}$ & $\begin{array}{c}6,24 \pm \\
0,53\end{array}$ & $\begin{array}{c}6,20 \pm \\
0,53\end{array}$ & $\begin{array}{c}6,23 \pm \\
0,52\end{array}$ & $\begin{array}{c}6,18 \pm \\
0,55\end{array}$ & $\begin{array}{c}6,16 \pm \\
0,53\end{array}$ & $\begin{array}{c}5,90 \pm \\
0,72\end{array}$ & 6,0 a 9,0 & 5,0 a 9,0 \\
\hline Dureza $\left(\mathrm{mg} \mathrm{CaCO}_{3} \mathrm{~L}^{-1}\right)$ & $\begin{array}{c}17,16 \pm \\
2,05\end{array}$ & $\begin{array}{c}19,14 \pm \\
1,02\end{array}$ & $\begin{array}{c}18,99 \pm \\
1,58\end{array}$ & $\begin{array}{c}18,66 \pm \\
0,98\end{array}$ & $\begin{array}{c}17,16 \pm \\
1,62\end{array}$ & $\begin{array}{c}19,14 \pm \\
3,47\end{array}$ & $* *$ & $* *$ \\
\hline Condutividade $\left(\mu \mathrm{S} \mathrm{cm}^{-1}\right)$ & $\begin{array}{c}66,17 \pm \\
9,28\end{array}$ & $\begin{array}{c}72,83 \pm \\
8,89\end{array}$ & $\begin{array}{c}75,00 \pm \\
8,22\end{array}$ & $\begin{array}{c}68,33 \pm \\
10,42\end{array}$ & $\begin{array}{c}66,33 \pm \\
10,56\end{array}$ & $\begin{array}{c}80,83 \pm \\
16,58\end{array}$ & $* *$ & $* *$ \\
\hline Alcalinidade $\left(\mathrm{mg} \mathrm{CaCO}_{3} \mathrm{~L}^{-1}\right)$ & $\begin{array}{c}22,36 \pm \\
3,93\end{array}$ & $\begin{array}{c}27,44 \pm \\
5,01\end{array}$ & $\begin{array}{c}24,75 \pm \\
1,49\end{array}$ & $\begin{array}{c}22,35 \pm \\
2,61\end{array}$ & $\begin{array}{c}23,96 \pm \\
4,67\end{array}$ & $\begin{array}{c}23,03 \pm \\
4,08\end{array}$ & $* *$ & $* *$ \\
\hline Clorofila a $\left(\mu \mathrm{g} \mathrm{L}^{-1}\right)$ & $\begin{array}{c}2,87 \pm \\
3,13\end{array}$ & $\begin{array}{c}52,62 \pm \\
34,60\end{array}$ & $\begin{array}{c}60,03 \pm \\
43,79\end{array}$ & $\begin{array}{c}4,25 \pm \\
4,06\end{array}$ & $\begin{array}{c}2,87 \pm \\
2,41\end{array}$ & $\begin{array}{c}3,03 \pm \\
2,99\end{array}$ & $\leq 30,0$ & $\leq 30,0$ \\
\hline Fósforo total (mg L-1) & $\begin{array}{c}0,04 \pm \\
0,02\end{array}$ & $\begin{array}{c}0,21 \pm \\
0,12\end{array}$ & $\begin{array}{c}0,25 \pm \\
0,09\end{array}$ & $\begin{array}{c}0,13 \pm \\
0,11\end{array}$ & $\begin{array}{c}0,05 \pm \\
0,05\end{array}$ & $\begin{array}{c}0,07 \pm \\
0,02\end{array}$ & $\leq 0,05$ & $\leq 0,05$ \\
\hline Nitrogênio total $\left(\mathrm{mg} \mathrm{L}^{-1}\right)$ & $\begin{array}{c}0,20 \pm \\
0,12\end{array}$ & $\begin{array}{c}1,10 \pm \\
0,91\end{array}$ & $\begin{array}{c}1,28 \pm \\
1,18\end{array}$ & $\begin{array}{c}0,33 \pm \\
0,17\end{array}$ & $\begin{array}{c}0,26 \pm \\
0,17\end{array}$ & $\begin{array}{c}0,34 \pm \\
0,20\end{array}$ & $\leq 2,18 * * *$ & 1,27 \\
\hline Nitrogênio amoniacal total $\left(\mathrm{mg} \mathrm{L}^{-1} \mathrm{~N}\right)$ & $\begin{array}{c}0,52 \pm \\
0,07\end{array}$ & $\begin{array}{c}0,83 \pm \\
0,59\end{array}$ & $\begin{array}{c}0,86 \pm \\
0,59\end{array}$ & $\begin{array}{c}0,59 \pm \\
0,15\end{array}$ & $\begin{array}{c}0,58 \pm \\
0,09\end{array}$ & $\begin{array}{c}0,61 \pm \\
0,09\end{array}$ & 0,5 a $3,7 *$ & 20,0 \\
\hline Amônia não ionizada $\left(\mathrm{mg} / \mathrm{L}^{-1}\right)$ & $\begin{array}{c}0,0008 \pm \\
0,0005\end{array}$ & $\begin{array}{c}0,0013 \pm \\
0,0013\end{array}$ & $\begin{array}{c}0,0015 \pm \\
0,0018\end{array}$ & $\begin{array}{c}0,0008 \pm \\
0,0007\end{array}$ & $\begin{array}{c}0,0007 \pm \\
0,0007\end{array}$ & $\begin{array}{c}0,0005 \pm \\
0,0005\end{array}$ & $* *$ & $* *$ \\
\hline Nitrito $\left(\mu \mathrm{g} \mathrm{L}^{-1}\right)$ & $\begin{array}{c}4,95 \pm \\
1,95\end{array}$ & $\begin{array}{c}41,27 \pm \\
90,11\end{array}$ & $\begin{array}{c}45,89 \pm \\
90,46\end{array}$ & $\begin{array}{c}9,99 \pm \\
9,48\end{array}$ & $\begin{array}{c}24,97 \pm \\
36,53\end{array}$ & $\begin{array}{c}13,85 \pm \\
10,82\end{array}$ & $\leq 1.000$ & $\leq 1.000$ \\
\hline Nitrato $\left(\mu \mathrm{g} \mathrm{L}^{-1}\right)$ & $\begin{array}{c}0,02 \pm \\
0,01\end{array}$ & $\begin{array}{c}0,02 \pm \\
0,02\end{array}$ & $\begin{array}{c}0,03 \pm \\
0,02\end{array}$ & $\begin{array}{c}0,09 \pm \\
0,08\end{array}$ & $\begin{array}{c}0,05 \pm \\
0,02\end{array}$ & $\begin{array}{c}0,07 \pm \\
0,03\end{array}$ & $\leq 10.000$ & $\leq 10.000$ \\
\hline Turbidez (UNT) & $\begin{array}{c}11,50 \pm \\
7,63\end{array}$ & $\begin{array}{c}36,53 \pm \\
7,08\end{array}$ & $\begin{array}{c}33,75 \pm \\
12,33\end{array}$ & $\begin{array}{c}45,08 \pm \\
59,24\end{array}$ & $\begin{array}{c}56,28 \pm \\
81,85\end{array}$ & $\begin{array}{c}48,73 \pm \\
69,99\end{array}$ & $\leq 100,0$ & $\leq 100,0$ \\
\hline Oxigênio dissolvido (mg L-1) & $\begin{array}{c}6,19 \pm \\
0,81\end{array}$ & $\begin{array}{c}6,19 \pm \\
1,23\end{array}$ & $\begin{array}{c}5,21 \pm \\
0,66\end{array}$ & $\begin{array}{c}7,18 \pm \\
0,35\end{array}$ & $\begin{array}{c}7,59 \pm \\
0,36\end{array}$ & $\begin{array}{c}7,38 \pm \\
0,63\end{array}$ & $\geq 5,0$ & $\geq 5,0$ \\
\hline Matéria orgânica $\left(\mathrm{mg} \mathrm{L}^{-1}\right)$ & $\begin{array}{c}12,23 \pm \\
21,04\end{array}$ & $\begin{array}{c}23,07 \pm \\
23,82\end{array}$ & $\begin{array}{c}20,39 \pm \\
29,91\end{array}$ & $\begin{array}{c}27,36 \pm \\
35,73\end{array}$ & $\begin{array}{c}29,22 \pm \\
44,99\end{array}$ & $\begin{array}{c}34,03 \pm \\
60,17\end{array}$ & $* *$ & $* *$ \\
\hline
\end{tabular}

\footnotetext{
*limite máximo de $3,7 \mathrm{mg} \mathrm{L}^{-1}$ para $\mathrm{pH} \leq 7,5$; ** Valores não disponíveis na resolução do CONAMA (2005); ***Ambiente Lótico.
} 
Tabela 3 - Medições realizadas na água de cultivo, utilizada no grupo controle, antes e após correção de variáveis físicas e químicas (médias \pm desvio padrão) conforme ABNT (2005).

\begin{tabular}{|c|c|c|c|}
\hline Variáveis & Controle antes da correção ${ }^{(1)}$ & Controle depois da correção ${ }^{(1)}$ & ABNT (2005) \\
\hline Temperatura da água $\left({ }^{\circ} \mathrm{C}\right)$ & $25,09 \pm 1,82$ & $24,7 \pm 0,83$ & $25 \pm 1$ \\
\hline $\mathrm{pH}$ & $6,90 \pm 0,93$ & $7,29 \pm 0,14$ & 7,0 a 7,6 \\
\hline Dureza $\left(\mathrm{mg} \mathrm{CaCO}_{3} \mathrm{~L}^{-1}\right)$ & $31,24 \pm 3,60$ & $43,56 \pm 1,25$ & 40 a 48 \\
\hline Condutividade $\left(\mu \mathrm{S} \mathrm{cm}^{-1}\right)$ & $118,40 \pm 19,55$ & $177,63 \pm 15,31$ & 72 a 212 \\
\hline Alcalinidade $\left(\mathrm{mg} \mathrm{CaCO}_{3} \mathrm{~L}^{-1}\right)$ & $23,36 \pm 2,38$ & Sem alteração & $*$ \\
\hline Fósforo total (mg L $\left.{ }^{-1}\right)$ & $0,12 \pm 0,02$ & Sem alteração & $*$ \\
\hline Nitrito $\left(\mathrm{mg} \mathrm{L}^{-1}\right)$ & $0,07 \pm 0,06$ & Sem alteração & $*$ \\
\hline Nitrato $\left(\mathrm{mg} \mathrm{L}^{-1}\right)$ & $0,81 \pm 0,17$ & Sem alteração & $*$ \\
\hline Turbidez (UNT) & $6,70 \pm 6,70$ & Sem alteração & $*$ \\
\hline Nitrogênio amoniacal total $\left(\mathrm{mg} \mathrm{L}^{-1}\right)$ & $0,58 \pm 0,08$ & Sem alteração & $*$ \\
\hline Nitrogênio total (mg L $\left.{ }^{-1}\right)$ & $0,65 \pm 0,19$ & Sem alteração & $*$ \\
\hline Amônia não ionizada (mg L L $\left.{ }^{-1}\right)$ & $0,0055 \pm 0,0045$ & Sem alteração & $*$ \\
\hline Oxigênio dissolvido (mg L $\left.{ }^{-1}\right)$ & $7,83 \pm 0,24$ & $7,80 \pm 0,20$ & $\geq 3,0$ \\
\hline
\end{tabular}

${ }^{(1)}$ Correção = ajustes de Dureza e pH; *Valores não disponíveis pela ABNT (2005).

conhecido como antagonismo (Aragão \& Araújo, 2006), como ocorreu no último ensaio, que apontou a ausência da toxicidade para o ponto $\mathrm{P} 1$. Os valores de condutividade obtidos, dos pontos P1 a P6, mantiveram-se sempre dentro de uma faixa, entre 66,2 a $80,8 \mu \mathrm{S} \mathrm{cm}^{-1}$, valores inferiores quando comparado ao grupo controle (Tabela 3 ).

Sipaúba-Tavares \& Rocha (2003) descreveram que a causa mais imediata sobre alteração na capacidade reprodutiva do zooplâncton relaciona-se às condições ambientais desfavoráveis, incluindo superpopulações e a deficiência de compostos orgânicos e inorgânicos no meio. As baixas concentrações de fósforo e nitrogênio (Tabela 2), especialmente em relação ao afluente (P1), podem ter causado toxicidade aos organismos-teste, pois estes elementos são os principais nutrientes necessários ao desenvolvimento de vários organismos aquáticos. Este aspecto pode ser explicado pela presença de grande número de plantas aquáticas (macrófitas) somente na represa de abastecimento (Represa do Borba), que funcionam como verdadeiros biofiltros para estes elementos. Por outro lado, o excesso destes elementos químicos, observado em outros pontos de amostragem, também pode ter causado toxicidade, nestes casos, crônica. Os maiores valores encontrados de fósforo (Tabela 2) foram registrados nas amostras do viveiro (P2) e em seu efluente (P3). Os valores destes pontos não atenderam aos padrões de qualidade da Resolução CONAMA (2005) para ambiente lótico (Tabela 2). Isto pode ser explicado, devido ao manejo de arraçoamento, ao tempo de residência da água e à inexistência de tratamento de efluente nesse local. Como demonstrado por Stephens \& Farris (2004 a,b) em ensaios agudos e crônicos, utilizando Ceriodaphnia dubia para efluentes de viveiro de catfish (Ictalurus punctatus), os resultados indicaram que valores acima de $0,10 \mathrm{mg} \mathrm{L}^{-1}$ de fósforo total causaram essa mesma toxicidade. Desse modo, a suspeita do fósforo como condicionante de toxicidade poderia ser levantada no presente estudo, especialmente para os pontos $\mathrm{P} 2$ e $\mathrm{P} 3$, cujos valores de fósforo registrados na Tabela $2\left(0,21 \mathrm{e} 0,25 \mathrm{mg} \mathrm{L}^{-1}\right)$ excederam ao valor de $0,10 \mathrm{mg} \mathrm{L}^{-1}$, considerado como tóxico para C. dubia pelos autores anteriormente mencionados.

Segundo Stephens \& Farris (2004b), o nitrogênio amoniacal total ou amônia total, tem efeito tóxico agudo para $C$. dubia na faixa de 0,53 a $4,94 \mathrm{mg} \mathrm{L}^{-1}\left(\mathrm{CL}_{50}\right)$ e, para toxicidade crônica, sua reprodução foi afetada em $0,46 \mathrm{mg} \mathrm{L}^{-1}$. Esses valores representam números significativos à maioria dos resultados médios observados no presente estudo (Tabela 2), levando-se à hipótese de que a amônia poderia ser mais um elemento que estivesse condicionando a toxicidade observada neste trabalho. No entanto, Andersen \& Buckley (1998) realizaram testes de toxicidade aguda com C. dubia, analisando os efeitos da amônia não ionizada $\left(\mathrm{NH}_{3}-\mathrm{N}\right)$, cujas concentrações mínima e máxima que afetaram os organismos, entre 24 a 48 horas, considerando os valores de amônia total $\left(9,31 \mathrm{mg} \mathrm{L}^{-1}\right), \mathrm{pH}$ $(8,0)$ e temperatura $\left(25{ }^{\circ} \mathrm{C}\right)$, foram de $0,56 \mathrm{mg} \mathrm{L}^{-1}(4-8 \%$ dos organismos) e $2,36 \mathrm{mg} \mathrm{L}^{-1}$ (84-99\% dos organismos), resultando em média de 1,73 $\pm 0,19 \mathrm{mg} \mathrm{L}^{-1}$ e 1,18 $\pm 0,10 \mathrm{mg} \mathrm{L}^{-1}$, respectivamente, para $\mathrm{CL}_{50: 24 \mathrm{~h}}$ e $\mathrm{CL}_{50: 48 \mathrm{~h}}$. Quando comparados aos resultados do presente trabalho (Tabela 2), os valores mínimos e máximos de $\mathrm{NH}_{3}-\mathrm{N}$ (para $\mathrm{pH}$ igual a 6,0 e temperatura de $26^{\circ} \mathrm{C}$ ), corresponderam, respectivamente, a $0,0005 \mathrm{mg} \mathrm{L}^{-1}(\mathrm{P} 6)$ e $0,0015 \mathrm{mg} \mathrm{L}^{-1}(\mathrm{P} 3)$; valores muito abaixo das concentrações que causariam toxicidade aguda, segundo os resultados dos autores anteriormente mencionados.

Os elevados teores de clorofila $a$ (Tabela 2) estiveram diretamente relacionados aos pontos $\mathrm{P} 2$ e P3, locais diretamente influenciados pelo manejo de arraçoamento. A acentuada concentração dos compostos nutricionais da ração, nesses dois pontos, pode ter favorecido o crescimento do fitoplâncton, explicado pelo resultado elevado de clorofila $a$, que ultrapassou a recomendação do CONAMA (2005). 
Todos os valores registrados para turbidez (Tabela 2) estiveram dentro da recomendação CONAMA (2005). O aumento destes valores nos pontos P4, P5 e P6 pode estar relacionado à precipitação pluviométrica que esteve bastante elevada no mês de janeiro de 2007 (50,6 mm), segundo os registros locais (APTA, 2007). De acordo com Gentil (2007), a variável turbidez resulta da presença de partículas em suspensão na água, tais como bactérias, fitoplâncton e substâncias orgânicas e inorgânicas, advindas de processos erosivos do solo adjacente ou da ressuspensão do sedimento. Por isso, nos demais pontos (P1, P2 e P3) não se registrou turbidez elevada para o mesmo período, pois o afluente ( $\mathrm{P} 1)$ escoa através de um condutor e uma canaleta de concreto (leito artificial), evitando aumento significativo na ressuspensão dos sedimentos, o que não ocorreu nos locais dos pontos P4, P5 e P6 (leito natural).

O cálculo do índice de estado trófico de Carlson demonstrou estado de eutrofização em todos os pontos, com exceção do ponto P1 com estado mesotrófico (Tabela 4). Estes resultados evidenciaram que o processo de eutrofização estava ocorrendo nos pontos P1, P5 e P6 e o estado de hipereutrofização nos pontos $\mathrm{P} 2$, P3 e P4, devido ao aumento das cargas externas de nutrientes, possivelmente, atribuído ao manejo realizado com ração.

\section{Outros aspectos relevantes}

No ponto de lançamento do efluente no corpo receptor (P4) os resultados de toxicidade não seguem uma regra padrão. Um exemplo disso foi a análise do mês de dezembro de 2006 ( $2^{\mathrm{a}}$ coleta) que apresentou toxicidade crônica diferente do resultado esperado para este ponto, pois seus afluentes P3 e P5 apresentaram toxicidade aguda (Figura 2). A explicação pode estar na dinâmica da mistura dos contribuintes neste ponto, que apresenta características heterogêneas, informando que o resultado obtido neste local não pode ser conclusivo para o estudo em questão.

À montante do ponto de mistura (P5) aflue o excedente da Represa do Borba e, dessa maneira, os resultados de toxicidade foram muito semelhantes aos do ponto P1, para todas as coletas, com exceção da $6^{\text {a }}$ coleta (Figura 2). A diferença entre estes pontos foi constatada com relação ao número de neonatos, apresentando menor reprodução no ponto P5. Observando a disposição do viveiro estudado dentro do empreendimento, nota-se que há outros dois viveiros de dimensões semelhantes e posicionados à montante do viveiro de estudo. Este aspecto pode ter contribuído também para os resultados de toxicidade observados nos pontos $\mathrm{P} 4$ e P6. Na $6^{\mathrm{a}}$ coleta, a toxicidade do ponto P5 manifestou-se de forma crônica, onde, comparada com o ponto $\mathrm{P} 1$, reforça a hipótese de que o corpo d'água receptor sofre influência de outros contribuintes.

A toxicidade apresentada no afluente (P1) pode, ainda, ser explicada pela grande precipitação pluviométrica ocorrida nos meses de novembro, janeiro e fevereiro, podendo ter causado possível diluição de nutrientes e transporte de resíduos (orgânicos ou inorgânicos), interferindo na sobrevivência e na reprodução do organismo-teste $C$. dubia. Este aspecto pode ser observado na correlação inversa existente entre os dados de precipitação e as observações relativas à reprodução do referido organismo utilizado nos ensaios (Figura 5), embora o coeficiente de correlação $\left(\mathrm{R}^{2}\right)$ seja considerado baixo.

Segundo as interpretações da resolução CONAMA(2005), a toxicidade do corpo hídrico receptor não deve ser alterada após o lançamento de efluentes no mesmo. Transportando essas informações para o presente estudo, pode-se dizer que a situação ideal seria estabelecida sempre que P4 e P6 tivessem demonstrado resultados de ação tóxica igual ou inferior a P5. Este aspecto foi observado no presente estudo (Figura 2), sugerindo que o lançamento do efluente de piscicultura, nas condições ecotoxicológicas estudadas, não proporcionou o aumento do impacto negativo ao meio ambiente. Inclusive, verificou-se, que

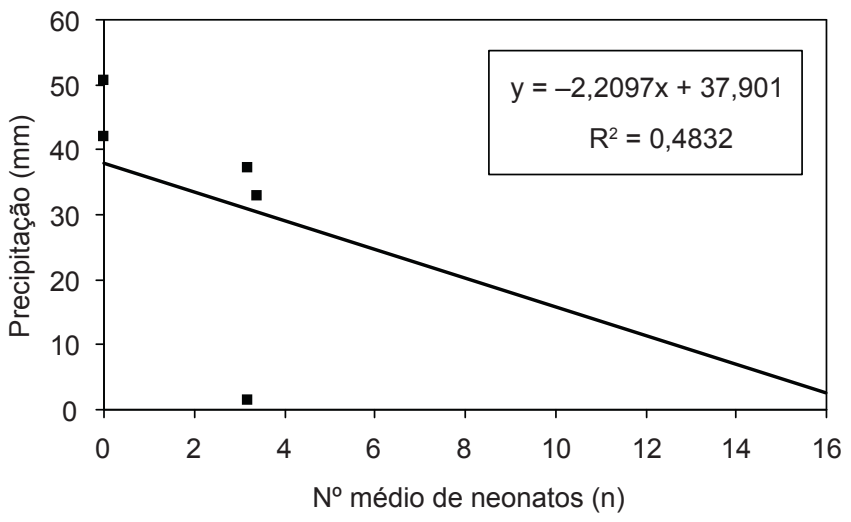

Figura 5 - Correlação entre as médias de precipitação e reprodução de C. dubia em amostras do ponto P1.

Tabela 4 - Estado trófico nos pontos de coleta, de acordo com o Índice de CARLSON alterado por KRATZER \& BREZONIK, (1981).

\begin{tabular}{|c|c|c|c|c|c|c|c|c|c|c|c|c|c|c|c|c|c|c|}
\hline \multirow[t]{2}{*}{ Coletas } & \multicolumn{3}{|c|}{ P1 } & \multicolumn{3}{|c|}{ P2 } & \multicolumn{3}{|c|}{ P3 } & \multicolumn{3}{|c|}{ P4 } & \multicolumn{3}{|c|}{ P5 } & \multicolumn{3}{|c|}{ P6 } \\
\hline & $\mathbf{p}$ & cl.a & iet & $\mathbf{p}$ & cl.a & iet & $\mathbf{p}$ & cl.a & iet & $\mathbf{p}$ & cl.a & iet & $\mathbf{p}$ & cl.a & iet & $\mathbf{p}$ & cl.a & iet \\
\hline $\mathrm{C} 1$ & 43 & 0,9 & 51 & 134 & 20,9 & 67 & 118 & 13,7 & 66 & 51 & 0,9 & 53 & 28 & 2,7 & 45 & 37 & 0,9 & 49 \\
\hline $\mathrm{C} 2$ & 38 & 1,8 & 49 & 233 & 38,2 & 75 & 251 & 24,6 & 76 & 119 & 1,8 & 66 & 31 & 0,9 & 46 & 64 & 0,9 & 57 \\
\hline $\mathrm{C} 3$ & 42 & 1,8 & 51 & 219 & 72,8 & 74 & 205 & 72,8 & 74 & 68 & 9,1 & 58 & 154 & 3,6 & 69 & 105 & 6,4 & 64 \\
\hline $\mathrm{C} 4$ & 22 & 9,1 & 41 & 27 & 9,1 & 44 & 237 & 61,0 & 76 & 337 & 9,1 & 81 & 27 & 7,3 & 44 & 49 & 7,3 & 53 \\
\hline $\mathrm{C} 5$ & 29 & 2,7 & 45 & 327 & 92,8 & 80 & 283 & 51,0 & 78 & 88 & 4,6 & 61 & 54 & 0,9 & 54 & 74 & 1,8 & 59 \\
\hline C6 & 79 & 0,9 & 60 & 330 & 81,9 & 80 & 379 & 137,1 & 82 & 95 & 0,0 & 62 & 26 & 1,8 & 44 & 59 & 0,9 & 56 \\
\hline Média & 2,2 & 2,9 & 51 & 211,7 & 52,6 & 74 & 245,5 & 60,0 & 76 & 126,4 & 4,25 & 67 & 53,4 & 2,8 & 54 & 64,7 & 3,0 & 57 \\
\hline
\end{tabular}

$\mathrm{p}=$ fósforo $\left(\mathrm{mg} \mathrm{L}^{-1}\right)$; cl.a = clorofila $a\left(\mu \mathrm{g} \mathrm{L}^{-1}\right)$; iet = índice de estado trófico; P1 a P6 = pontos de coleta. 
após 13 metros do ponto de lançamento do efluente (à jusante), houve uma ligeira redução dos efeitos tóxicos, sugerindo a ação de um processo natural de depuração.

De modo geral, não foi possível identificar um fator único que ocasionasse a toxicidade apresentada, mas sabe-se que os resultados sofreram influência sazonal, devido ao período chuvoso-quente, aliado às características específicas de cada ponto, assim como, a presença de diversas fontes pontuais de poluição que são lançadas na represa de abastecimento e pelo fato de que os ensaios de toxicidade não evidenciam quais agentes químicos estavam presentes na amostra (Aragão \& Araújo, 2006) e sim que havia a presença ou não de substâncias em quantidades capazes de provocar efeitos tóxicos agudos ou crônicos.

Estudos mais detalhados devem ser realizados para constatar as diversas hipóteses formuladas no presente trabalho e fomentar a principal causa que levou a toxicidade aos organismos-teste. Dentre estes estudos, destaca-se a identificação de fontes pontuais de poluentes, lançados pelas atividades realizadas no entorno do empreendimento de piscicultura, tais como lavoura e pecuária, que porventura poderiam estar contribuindo com a introdução de xenobióticos em geral, ou seja, pesticidas, metais, fármacos, hormônios, etc.

\section{CONCLUSÃO}

Analisando os dados obtidos, pode-se resumir que as amostras de água coletadas no viveiro de piscicultura e seus respectivos ensaios apresentaram toxicidade aguda e crônica ao organismo-teste Ceriodaphnia dubia. De acordo com os resultados das análises físicas e químicas, os baixos valores de dureza e $\mathrm{pH}$ das amostras estiveram relacionados como principais fatores abióticos que interferiram diretamente nas condições dos ensaios. Entretanto, as diferenças expressivas nos níveis de fósforo total e nitrogênio amoniacal total foram as variáveis de maiores suspeitas de condicionarem os resultados de toxicidade aguda e crônica aos organismos-teste. Também foram constatados diversos fatores externos e fontes pontuais de poluentes que podem ter afetado a qualidade das águas analisadas neste trabalho, confirmando que a fonte de abastecimento já chega ao local portando características tóxicas.

Concluiu-se que a atividade de piscicultura estudada não aumentou o grau de toxicidade para C. dubia e, em geral, houve uma melhora neste aspecto após o lançamento do efluente no corpo receptor. Porém, vale ressaltar que o alto grau de eutrofização dos pontos P2 (viveiro) e P3 (efluente) apontam para a necessidade de tratamento antes do seu despejo no corpo receptor, de acordo com os padrões estabelecidos, para corpos de água de classe 2, pela Resolução CONAMA 357/2005. Neste caso, recomenda-se: (a) controlar e/ou tratar as quantidades de fósforo e nitrogênio dentro do viveiro; (b) promover tratamento do efluente, antes de seu despejo no corpo hídrico; (c) realizar estudos mais detalhados dos possíveis agentes químicos de contaminação e suas devidas concentrações, como pesticidas, metais e outros produtos químicos que possam estar presentes na água destinada à piscicultura.
Agradecimentos - À FAPESP - Fundação de Amparo à Pesquisa do Estado de São Paulo, pela concessão do auxílio financeiro utilizado na realização deste estudo, conforme Processo no 05/05180-0. À Organon, parte da Schering-Plough Corporation pela doação de alguns equipamentos laboratoriais. Ao Núcleo de Aqüicultura do Pólo Regional de Desenvolvimento Tecnológico dos Agronegócios do Vale do Paraíba - APTA Regional - Agência Paulista de Tecnologia dos Agronegócios (SAA-SP), do município de Pindamonhangaba, especialmente à Pesquisadora Dra. Cleide Schmidt Romeiro Mainardes Pinto pelas valiosas informações prestadas e apoio logístico.

\section{REFERÊNCIAS BIBLIOGRÁFICAS}

ABNT, Associação Brasileira de Normas Técnicas, 2005, Ecotoxicologia Aquática - Toxicidade crônica - Método de ensaio com Ceriodaphnia spp (Crustacea, Cladocera). ABNTNBR 13373, 15p.

ANDERSEN, H. B. \& BUCKLEY, J. A., 1998, Acute Toxicity of Ammonia to Ceriodaphnia dubia and a Procedure to Improve Control Survival. Environmental Contamination and Toxicology. New York. 61: 116-122.

APHA, AWWA \& WEF, 2005, Standard Methods for the examination of Water and Wastewater. $21^{\mathrm{a}}$. ed. APHA-American Public Health Association, AWWA - American Water Works Association, and WPCF - Water Environment Federation., Washington, D.C. $1085 p$.

APTA, Agência Paulista de Tecnologia das Agronegócios, 2007, Relatório de Dados Meteorológicos dos meses de Junho de 1999 a Junho de 2007. Instituto Agronômico. Pólo Regional de Desenvolvimento Tecnológico dos Agronegócios do Vale do Paraíba. Pindamonhangaba, São Paulo, 97p.

ARAGÃO, M. A. \& ARAÚJO, R. P. A., 2006, Métodos de Ensaios de Toxicidade com Organismos Aquáticos. In: ZAGATTO, P. A. \& Bertoletti, E., 2006. Ecotoxicologia Aquática - Princípios e Aplicações. São Carlos, São Paulo, p. 117-152.

BOYD, C., 1990, Water quality in ponds for aquaculture. Auburn University, Alabama. Birmingham Publishing Co., Alabama, $482 \mathrm{p}$.

BOYD, C. E. \& TUCKER, C. S., 1998, Pond aquaculture water quality management. Kluwer Academic Publishers. Boston, $700 \mathrm{p}$.

BOWER, C.E. \& BIDWELL, J.P., 1978, Ionization of ammonia in seawater: effects of temperature, $\mathrm{pH}$, and salinity. J. Fish. Res. Board Can., 35: 1012-1016.

BRAGA, B., HESPANHOL, I., CONEJO, J. G. L. , BARROS, M. T. L., VERAS Jr., M. S. PORTO, M. F. A., NUCCI, N. L. R., JUlianO, N. M. A. \& EIGER, S., 2004, Introdução à engenharia ambiental. Prentice Hall, São Paulo, 305p.

CARLSON, R. C., 1977, A trophic state index for lakes. Limnology and Oceonography, 22: 361-369.

CETESB, 2007, Variáveis de qualidade das águas., São Paulo. Disponível em: URL: http//: www.cetesb.sp.gov.br/ Agua/rios/ variaveis.asp\#dbo>. Acesso em: jun. 2007.

CONAMA, 2005, Resolução $n^{\circ} 357$, de 17 de março de 2005. Diário Oficial da União, Brasília. Disponível em: URL: http//: www. mma.gov.br/port/conama/res/res05/res35705. pdf. Acesso em: maio. 2006. 23p.

COWGILL, U. M. \& MILAZZO, D. P., 1991, Demographic effects of salinity, water hardness and carbonate alkalinity on Daphnia magna and Ceriodaphnia dubia. Archiv f. Hydrobiologie., 122: 33-56. 
DOMINGUES, D. F. \& BERTOLETTI, E., 2006, Seleção, Manutenção e Cultivo de Organismos Aquáticos. pp. 153-184. In: Zagatto, P. A. \& Bertoletti, E. (ed.), Ecotoxicologia Aquática: Princípios e Aplicações. São Carlos, São Paulo, 464p.

GENTIL, R. C., 2007, Estrutura da comunidade fitoplanctônica de pesqueiros da Região Metropolitana de São Paulo, em dois periodos: primavera e verão. Tese de doutorado. Instituto de Botânica da Secretaria de Meio Ambiente do Estado de São Paulo, São Paulo, 186p.

GULLEY, D. D., BOELTER, A. M. \& BERGMAN, H. L., 1991, TOXSTAT 3.3.: Fish Physiology and Toxicology Laboratory. Dept. Zool. and Physiol., Univ. WY, Laramie, WY.

IBAMA, 2005, Estatísticas de Pesca. Instituto Brasileiro do Meio Ambiente e dos Recursos Naturais Renováveis, MMA. Brasília, 260p.

KRATZER, C.R.\& BREZONIK, P.L,. 1981, A Carlson-type trophic state index for nitrogen in Florida lakes. Water Resources Bulletin 17(4): 713-715.

KUBITZA, F., 1999, Nutrição e alimentação dos peixes cultivados. $3^{\text {rd }}$ ed., CIP - Universidade de São Paulo, Jundiaí, São Paulo, $123 \mathrm{p}$.

LEWIS, P. A., KLEMM, O. J., LAZORCHAK, J. M., NORBERGKING, T. J., PELTIER, W. H. \& HEBER, M. A., 1994, Short term methods for estimating the chronic toxicity of effluents and receiving water to freshwater organisms. $3^{\text {rd }}$ ed. Environmental Monitoring Systems Laboratory, Cincinnati Office of Research and Development, U.S. Environmental Protection Agency, Cincinnati, Ohio. EPA/600/4-91/002. 341p.

LOMBARDI, J. V., 2004, Fundamentos de Toxicologia Aquática. pp. 263-272 In: Ranzani- Paiva et al. (org.), Sanidade de organismos aquáticos. Ed. Varela, São Paulo, 426p.

MERCANTE, C. T. J. \& TUCCI-MOURA, A., 1999, Comparação entre os índices de Carlson e de Carlson modificado aplicados a dois ambientes aquáticos subtropicais. São Paulo, SP. Acta Limnológica Brasiliensia, 11: 1-14.

NORBERG-KING, T. J., 1993, A linear interpolation method for subletal toxicity: the inhibition concentration (ICp) approach. Version 2.0. National Effluent Toxicity Assessment Centre. Technical Report 03-93. Duluth, M. N. 13p.

OLIVEIRA-NETO, A. L., RIBEIRO, L., TRIBESS, T., TORRES, M. A., SOARES, C. H. L., PEDROSA, R. C., AGOSTINI, J., BUENO, A. \& WILHEM-FILHO, D., 2000, Estresse oxidativo em tilápia (Oreochromis niloticus) exposta ao efluente de industria têxtil. pp. 441- 449. In: E. L. G. Espíndola, C. M. R. Botta-Paschoal, O. Rocha, M. B. C. Bohrer \& L. A. Oliveira Neto (org.). Ecotoxicologia: perspectivas para o século XXI. Rima Editora, São Carlos, 575p.

PILLAY, T. V. R., 1992, Aquaculture and the Environment. Londres, Fishing News Books, 189p.

PORRELlO, S., LENZI, M., TOMASSETTI, P., PERSIA, E., FINOIA, M. G. \& MERCATALI, I., 2003, Reduction of aquaculture wastewater eutrophication by phytotreatment ponds system II. Nitrogen and phosphorus content in macroalgae and sediment. Aquaculture, Rome, Italy, 219: 531-544.

QUEIROZ, J. F. \& SILVEIRA, M. P., 2006, Recomendações Práticas para Melhorar a Qualidade da Água e dos Efluentes dos Viveiros de Aqüicultura. Circular Técnica da Embrapa no. 12. Jaguariúna, São Paulo. Disponível em URL: http//: www.cnpma. embrapa. com.br. Acesso em: jul. 2007. 14p.

SARTORY, D. P. \& GROBBELAAR, J. U., 1984, Extraction of chlorophyll a from freshwater phytoplankton for spectrophotometric analysis. Hydrobiologia, 114: 177-187.

SIPAÚBA-TAVARES, L. H. \& ROCHA, O., 2003, Produção de Plâncton (Fitoplâncton e Zooplâncton) para Alimentação de Organismos Aquáticos. São Carlos, São Paulo. Rima. 106p.

STEPHENS, W. W. \& FARRIS, J. L., 2004a, Instream community assessment of aquaculture effluents. Environmental Sciences Program., Arkansas State University. Arkansas, EUA. Aquaculture, 231: 149-162. 14p.

STEPHENS, W. W. \& FARRIS, J. L., 2004b, A biomonitoring approach to aquaculture effluent characterization in channel catfish fingerling production. Environmental Sciences Program., Arkansas State University. Arkansas, EUA. Aquaculture 241: 319-330. 12p.

TOMITA, R. Y., BEYRUTH, Z., SÁFADI, R. S. \& AITA-FONTES, A. F., 2004, Toxicidade da mistura dos herbicidas atrazina e diuron sobre Daphnia similis (Crustacea, Cladocera). Arquivos do Instituto Biológico, São Paulo, v. 71, n. Suplemento, p. 3063081.

UNEP-IETC (United Nations Environment Programme International Environmental Technology Centre), 2001, Planning and Management of Lakes and Reservoirs: An Integrated Approach to Eutrophication. Osaka/Shiga, Japão. 385p.

USEPA, 2002, Short-term methods for estimating the chronic toxicity of effluents and receiving waters to freshwater organisms. 4. ed. U.S. Environmental Protection Agency, Washington. D.C., EPA821-R-02-013

VALENTI, W. C., 2007, Brasil's Inland Aquaculture - Freshwater Fish Dominate Production. Centro de Aqüicultura da UNESP. Jaboticabal, São Paulo, 2p. 